\title{
The effects of polishing the fitting surface of acrylic base retainers on Methichillin resistance staphylococcus aureus; a laboratory study
}

\author{
Dheaa Al Groosh
}

MSc, PhD. Assistant Professor of Orthodontics, University of Baghdad /College of Dentistry

Jonathan Pratten

$\mathrm{PhD}$. Honorary lecturer, UCL/Eastman Dental Institute

Nigel Hunt

MSc, MOrthRCS, FOrthRCS, PhD. Professor of Orthodontics, UCL/Eastman Dental Institute

\begin{abstract}
This in vitro study evaluated the effects of polishing the fitting surface of two acrylic based matetrials on the surface characteristics and biofilm formation of Methicillin Resistance Staphylococcus aureus (MRSA) biofilms. A simulated mouth model (Constant Depth Film Fermenter) was used to produce biofilms on autopolymerised and heat cure acrylic substrata. Surface parameters included surface roughness, hydrophobicity and surface free energy was evaluated after using the conventional polishing procedure to samples simulating the clinical situation. The results showed that MRSA has successfully adhered and grown in all samples with a similar pattern without a significant difference between the recovered viable bacterial counts. The rough surface provide protected niche for MRSA against the dislodgment forces. In conclusion, the finding of suggested that polishing the fitting surface of acrylic base materials may facilitate MRSA biofilm removal.
\end{abstract}

KEY WORDS

MRSA Biofilm, Hawley retainer, surface roughness

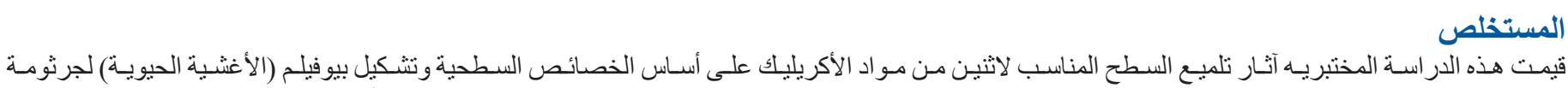

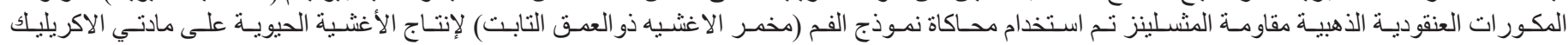

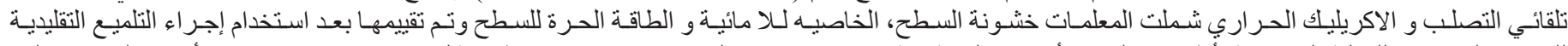

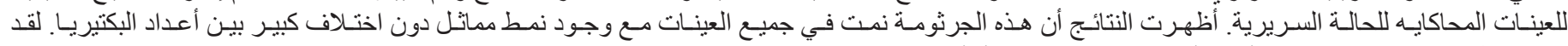

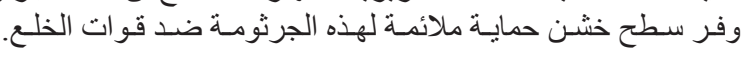

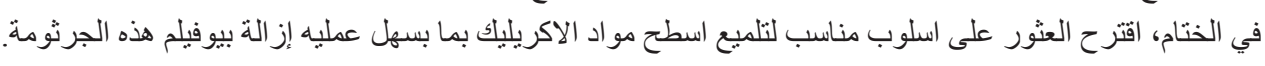

\section{INTRODUCTION:}

The oral cavity is one of the most heavily populated regions of the human body with regards to microorganisms. Various factors may influence the diversity of the oral microorganisms in an individual such as age, sex, genetics and diet ${ }^{(1)}$. However, it is difficult to define the composition of the oral microbiota precisely because of the frequent exposure to the exogenous microorganisms in water, food, air or during direct contact to other microbial communities. It has been suggested that the lack of adhesins and receptors are among the causes that discourage the exogenous microorganisms to bind or co-aggregate to the oral surfaces ${ }^{(2)}$.

It is not always true that the oral microbiota exhibit a beneficial effect on the host. Indeed, there is a dynamic association between humans and their microbiota ${ }^{(3)}$. The characteristic composition of the commensal oral microbiota can be disturbed by altering the habitat which affects the stability of the oral environment, such as $\mathrm{pH}$, the supply of oxygen and the relationship between the communities. These changes can lead to various oral diseases such as dental caries, gingivitis and periodontal disease ${ }^{(4,5)}$. Moreover, the oral cavity may act as a reservoir for infection at remote sites such as bacterial endocarditis or brain and liver abscesses when gaining access to the bloodstream via untreated carious lesions or the gingival crevice ${ }^{(6-8)}$. Indeed, it has been suggested that oral microorganisms may be diagnostic biomarkers for some diseases such as in pancreatic disease ${ }^{(9,10)}$.

Biomaterials are prone to microbial accumulation during and after implantation. The microorganisms adhere to these materials by either specific interaction or non-specific interactions ${ }^{(11,12)}$. Acrylic resins are widely used for the construction of various dental prosthesis including orthodontic appliances. These materials are prone to microbial adhesion and biofilm formation (13). Staphylococci and MRSA have the ability to adhere to acrylic base retainers and form biofilms ${ }^{(14)}$. Acrylic materials may act a reservoir for these opportunistic microorganisms.

The aim of this study was to find out whether polishing the fitting surface of acrylic base removable orthodontic retainer materials influences surface properties that discourage MRSA biofilm formation.

\section{MATERIALS AND METHODS}

Three moulds of silicone (irreversible silicone duplicating material, Dentaurum, Germany) were made from a smooth glass block $100 \mathrm{~mm}$ x $80 \mathrm{~mm}$ of known roughness value. A class IV stone (Crystacal 
$\mathrm{R}$, BPB Formula, UK) was vacuum mixed according to the manufacturer's instructions and poured to produce a positive replica for the reference block.

An acrylic sheets of $1.5 \mathrm{~mm}$ thickness of autopolymerised acrylic (Forestacryl, Forestadent, Germany) and heat cure acrylic resins (Meadway, Bracon Ltd., UK) were constructed, using the addition technique and the compression moulding technique respectively, according to the manufacturers' instructions ${ }^{(15)}$.

The acrylic sheets were then divided into two halves; one was finished using a conventional laboratory technique with a tungsten bur (Bracon) at $15000 \mathrm{rpm}$ followed by polishing with a slurry of pumice (Pumice, Dentsply, UK), water, bristle brush including lathe and Calico Mop (C\&L.E. Attenborough Ltd., Nottingham, UK) and polishing composition (Vonax, Canning-Lippert Ltd., Birmingham, UK). The surface of the other half was kept without modification to simulate the clinical condition.

Five samples of $15 \mathrm{~mm} \times 10 \mathrm{~mm}$ of each material described above were tested with regard to their hydrophobicity and surface free energy. The contact angle of distilled water (for hydrophobicity), glycerol (Sigma-Aldrich) and hexadecane (Sigma) were performed according to a sessile drop method ${ }^{(16)}$.

For measuring the surface roughness, five samples of $5 \mathrm{~mm}$ in diameter of heat cured and autopolymerised acrylic were analysed using atomic force microscope (AFM; XE 100 Park Instruments Korea) to measure the surface roughness value $\mathrm{Ra}$ (arithmetic roughness). The roughness value represents an area of $45 \times 45 \mu \mathrm{m}$ and consists of 512 x 512 pixels with a scan scale of $1 \mathrm{~Hz}$. The probe has a bending constant of $0.3 \mathrm{~N} / \mathrm{m}$.

In vitro studies were performed to assess the effects of different retainer materials and their surface properties on biofilm growth. For this purpose the Constant Depth Film Fermenter (John Parry Jones Engineering, Cardiff, UK) was used as described previously ${ }^{(17)}$.

The biofilm was quantified and viewed using the
(18).

The Results obtained from the biofilm assay were tested, after logarithmic transformation of the data, using independent student's t-test to compare the differences in the colony forming unit means.

\section{RESULTS}

Table 1 shows the surface physiochemical properties including surface roughness, hydrophobicity and surface free energy of the acrylic and thermoplastic samples. The surface roughness values of the autopolymerised acrylic samples were higher than that of the heat cure samples $(0.93 \mu \mathrm{m}$ and $0.66 \mu \mathrm{m}$ respectively). However, the polished samples were almost similar. It has also found that when the surface roughness increases the contact angle increase. Hence, the material became more hydrophobic. Simultaneously, the samples showed no difference in total free energy and Van der Waals forces.

The deposition of MRSA on heat cured and autopolymerised acrylic samples mimicking the clinical situation and those finished and polished using laboratory polishing procedures are shown in figures 1 and 2 . There were no significant differences in the recovered MRSA counts between the polished and unpolished acrylic samples on either of the resin materials although the bacterial counts recovered from the polished surfaces were less than that of the unpolished ones.

However, visually the SEM and the CLSM micrographs (figure 3 ) show that the pattern of MRSA aggregation on the clinically simulated samples was different from that occurring on the conventionally polished ones. The later showed that the bacteria adhered initially in the rough irregularities remaining following the conventional polishing procedure, leaving the polished area with very few numbers of bacteria. The same pattern of bacterial distribution was detected on the clinically simulated samples where the MRSA aggregate was denser in the deeper irregularities within the rough areas of the surface, however, the bacteria still aggregated on the rest of the sample. same protocols as described by Morgan and Wilson

Table 1: Surface roughness (Ra in $\mu \mathrm{m}$ ), hydrophobicity (in degrees) and surface free energy parameters (in $\mathrm{mJ} / \mathrm{m} 2$ ) of heat cure acrylic and autopolymerised acrylic samples polished using the conventional polishing procedure. The surface free energy parameters include Lifshitz-Van der Walls (LW), electron donor (-), electron acceptor (+), acid-base component $(\mathrm{AB})$ and total free energy (Total).

\begin{tabular}{|c|c|c|c|c|c|c|c|}
\hline \multirow{2}{*}{ Materials } & \multirow{2}{*}{ Surface roughness } & \multirow{2}{*}{ Hydrophobicity } & \multicolumn{5}{|c|}{ Surface Free Energy } \\
\hline & & & LW & $(+)$ & $(-)$ & $A B$ & Total \\
\hline Cold cure acrylic unpolished & $0.93 \pm 0.45$ & $75.7 \pm 4.5$ & 21.8 & 0.005 & 18.21 & 0.6 & 22.4 \\
\hline Cold cure acrylic polished & $0.27 \pm 0.19$ & $72.1 \pm 5.9$ & 19.44 & 0.16 & 20.96 & 3.66 & 23.1 \\
\hline Heat cure acrylic unpolished & $0.66 \pm 0.23$ & $81.1 \pm 3.1$ & 21.24 & 0.01 & 14.72 & 0.77 & 22.01 \\
\hline Heat cure acrylic polished & $0.25 \pm 0.1$ & $75.9 \pm 6.3$ & 21.9 & 0.01 & 25.05 & 1 & 22.9 \\
\hline
\end{tabular}



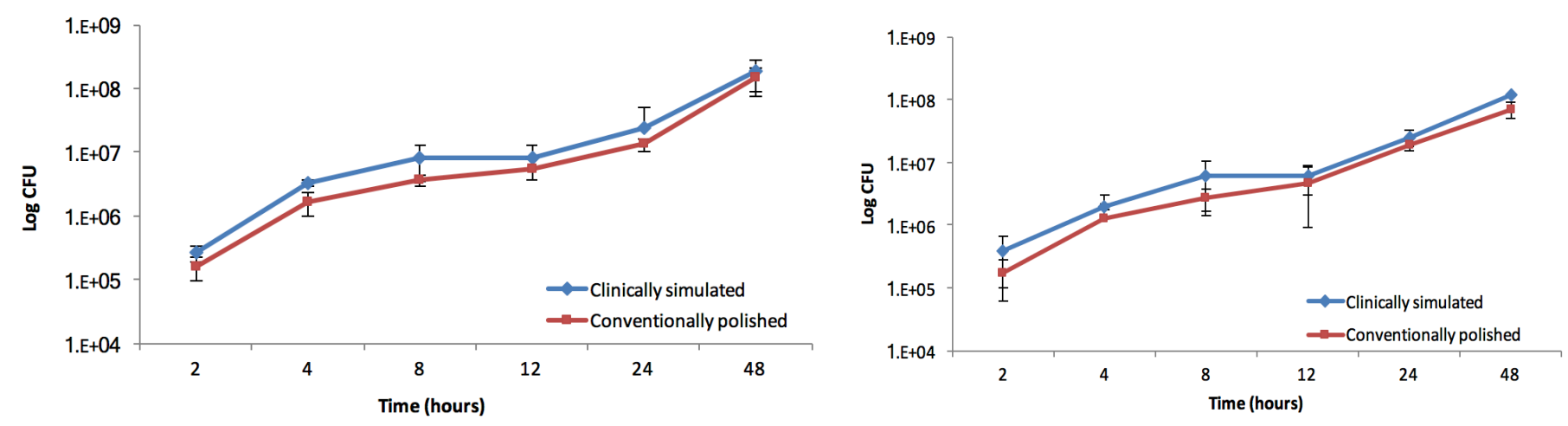

Figure 1: Viable counts of MRSA deposition on clinically simulated autopolymerised acrylic samples versus conventional (laboratory) finished and polished samples.

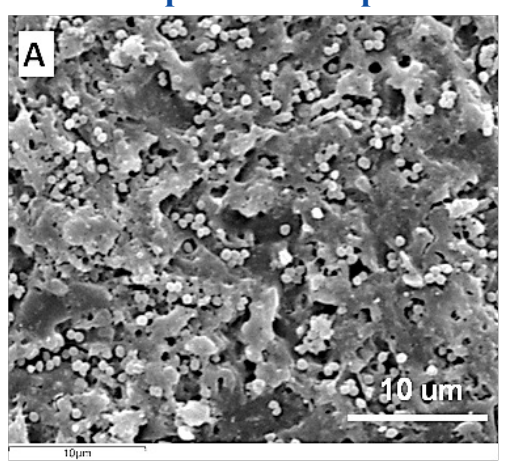

Figure 2: Viable counts of MRSA deposition on clinically simulated heat-cured acrylic samples and conventionally (laboratory) finished and polished samples.
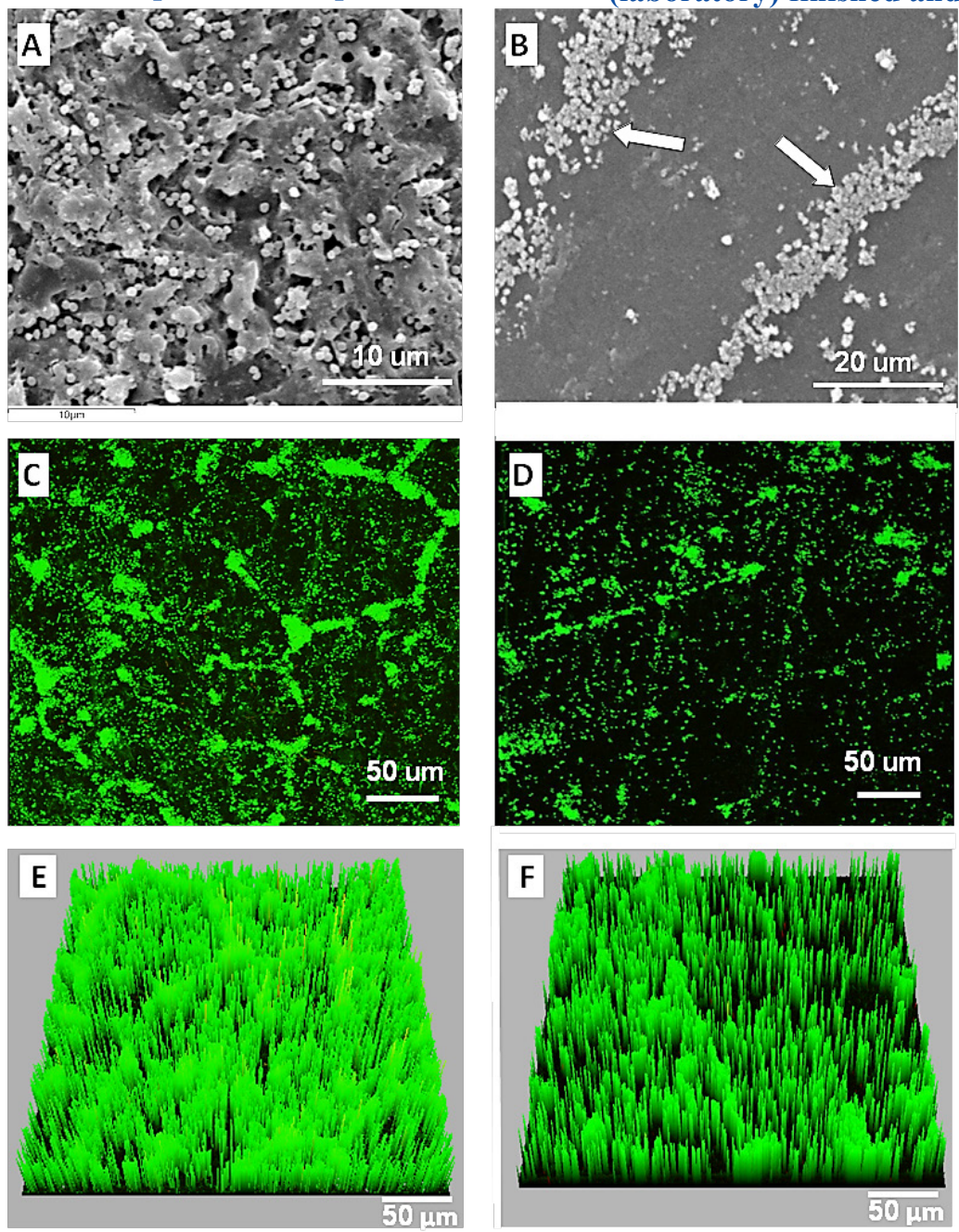

Figure 3: SEM and CLSM images with three dimensional representation of 24h MRSA deposition on heat cured acrylic samples receiving surface modification. Unpolished heat cured acrylic (simulate clinical condition) (A, C and E); Polished heat cured acrylic sample using conventional polishing procedures $(B, D$ and $F)$. The arrows refer to the distribution of bacterial attachment.

\section{DISCUSSION}

Removable orthodontic retainers are intraoral implants and are subjected to the same problems as other implants in that they are susceptible to biofilm accumulation. In a previous study MRSA was recovered from the retainers and the oral cavity of full time retainer wearers ${ }^{(14)}$. It is well known that surface roughness increases the physical surface area of a material and may provide protected niches where the bacteria are sheltered against the dislodgement forces such as mechanical brushing. A threshold surface roughness value for microbial aggregation of $0.2 \mu \mathrm{m}$ has been suggested by some in vivo studies in that below this value, no further reduction in microbial accumulation could be detected ${ }^{(19)}$.

To ensure clinical relevance, the biofilm assay was undertaken using materials that are already applied in orthodontics; therefore, the substratum was fabricated 
following the manufacturer's recommendations and finished using the same laboratory procedure. Furthermore, a CDFF was used which generates large numbers of reproducible biofilms with conditions similar to that of the oral cavity ${ }^{(20)}$.

Several studies have been conducted to find the effect of surface roughness of acrylic materials on Streptococcus spp. or Candida spp. attachment ${ }^{(18,21)}$. However, studies involving staphylococci biofilms have only been carried out using bone cement as a substratum ${ }^{(22)}$.

The results obtained from the current study revealed that all the tested samples showed hydrophilic surfaces and when the surface became rough, the contact angle increased and the surface exhibited more hydrophobic characteristics. This may be due to the barrier effect of the surface irregularities which may prevent the spread of the water drop. This comes in agreement with Crick and Parkin ${ }^{(23)}$ who found that the wetting characteristic changes when a surface becomes rougher.

Although the surface free energy is influenced by the chemical composition of a substratum and the fabrication procedure which in turn affects the surface properties of that material ${ }^{(24)}$, the current study showed that there were no marked differences in the total surface free energy and Van der Walls force regardless of difference in surface roughness.

The biofilm data showed that MRSA successfully adhered and colonized forming biofilms on the surface of acrylic substrata constructed simulating the clinical condition. When the surface roughness of a material increased the bacterial count increased regardless of the type of tested material; however, there was no significant difference between the clinically simulated and the laboratory polished samples. The result of this study showed that MRSA was detected within the microscopic surface irregularities of the unpolished samples and accumulated initially in the rough areas within the polished acrylic samples. The surface free energy parameters did not have an obvious effect on bacterial attachment. Surface irregularities in rough material increase the physical surface area and provide protected niches that encourage bacterial adhesion ${ }^{(25)}$. CONCLUSION

The data obtained from the current study showed that acrylic materials have shown favourable surface characteristics for MRSA adhesion and biofilm formation. Surface roughness may influence MRSA biofilm formation on acrylic. Smooth surfaces may facilitate biofilm removal, whereas a rough surface not only increases the physical surface area but also provides shelter for the adhered bacteria against mechanical dislodging forces and, therefore, anchor the established biofilm.

\section{REFERENCES}

1. Schenkein HA, Burmeister JA, Koertge TE, Brooks CN, Best AM, Moore LV, et al. The influence of race and gender on periodontal microflora. Journal of periodontology. 1993 Apr;64(4):292-6. PubMed PMID: 8387107

2. Wade WG. The oral microbiome in health and disease. Pharmacological research : the official journal of the Italian Pharmacological Society. 2013 Mar;69(1):137-43. PubMed PMID: 23201354.

3. Todar K. Pathogenic E. coli. Online textbook of bacteriology 2007.

4. Socransky SS, Haffajee AD. Implications of periodontal microbiology for the treatment of periodontal infections. Compendium. 1994 (18):S684-5, 8-93; quiz S714-7. PubMed PMID: 8039206.

5. Sbordone L, Bortolaia C. Oral microbial biofilms and plaque-related diseases: microbial communities and their role in the shift from oral health to disease. Clinical oral investigations. 2003 Dec;7(4):181-8. PubMed PMID: 14598129.

6. Mylonakis E, Calderwood SB. Infective endocarditis in adults. The New England journal of medicine. 2001 Nov 1;345(18):1318-30. PubMed PMID: 11794152.

7. SchiffE, Pick N, Oliven A, Odeh M. Multiple liver abscesses after dental treatment. Journal of clinical gastroenterology. 2003 Apr;36(4):369-71. PubMed PMID: 12642750.

8. Marques da Silva R, Caugant DA, Josefsen R, Tronstad L, Olsen I. Characterization of Streptococcus constellatus strains recovered from a brain abscess and periodontal pockets in an immunocompromised patient. Journal of periodontology. 2004 Dec;75(12):1720-3. PubMed PMID: 15732877.

9. Ahn J, Chen CY, Hayes RB. Oral microbiome and oral and gastrointestinal cancer risk. Cancer causes \& control : CCC. 2012 Mar;23(3):399-404. PubMed PMID: 22271008.

10. Farrell JJ, Zhang L, Zhou H, Chia D, Elashoff D, Akin D, et al. Variations of oral microbiota are associated with pancreatic diseases including pancreatic cancer. Gut. 2012 Apr;61(4):582-8. PubMed PMID: 21994333.

11. Kolenbrander PE, London J. Adhere today, here tomorrow: oral bacterial adherence. Journal of bacteriology. 1993 Jun;175(11):3247-52. PubMed PMID: 8501028. Pubmed Central PMCID: 204720.

12. Bos R, van der Mei HC, Busscher HJ. Physico-chemistry of initial microbial adhesive interactions--its mechanisms and methods for study. FEMS microbiology reviews. 1999 Apr;23(2):179-230. PubMed PMID: 10234844.

13. Kuhar M, Funduk N. Effects of polishing techniques on the surface roughness of acrylic denture base resins. The Journal of prosthetic dentistry. 2005 Jan;93(1):76-85. PubMed PMID: 15624002.

14. Al Groosh D, Roudsari GB, Moles DR, Ready D, Noar JH, Pratten J. The prevalence of opportunistic pathogens associated with intraoral implants. Letters in applied microbiology. 2011 May;52(5):501-5. PubMed PMID: 21332760.

15. Goncalves TS, Spohr AM, de Souza RM, Macedo de Menezes L. Surface roughness of auto polymerized acrylic resin according to different manipulation and polishing 
methods: an in situ evaluation. The Angle orthodontist. 2008 Sep;78(5):931-4. PubMed PMID: 18298208.

16. Perni S, Prokopovich P, Piccirillo C, Pratten J, Parkin IP, Wilson M. Toluidine blue-containing polymers exhibit potent bactericidal activity when irradiated with red laser light. Journal of Materials Chemistry. 2009;19(18):271523.

17. Pratten J. Growing oral biofilms in a constant depth film fermentor (CDFF). Current protocols in microbiology. 2007 Aug;Chapter 1:Unit 1B 5. PubMed PMID: 18770599.

18. Morgan TD, Wilson M. The effects of surface roughness and type of denture acrylic on biofilm formation by Streptococcus oralis in a constant depth film fermentor. Journal of applied microbiology. 2001 Jul;91(1):47-53. PubMed PMID: 11442713.

19. Bollen CM, Lambrechts P, Quirynen M. Comparison of surface roughness of oral hard materials to the threshold surface roughness for bacterial plaque retention: a review of the literature. Dental materials : official publication of the Academy of Dental Materials. 1997 Jul;13(4):258-69. PubMed PMID: 11696906.

20. O'Neill JF. Characterisation and susceptibility to leathal photosensitisation of in vitro-grown sub-gingival biofilms.: University College London; 2006.

21. Radford DR, Sweet SP, Challacombe SJ, Walter JD. Adherence of Candida albicans to denture-base materials with different surface finishes. Journal of dentistry. 1998 Sep;26(7):577-83. PubMed PMID: 9754746.

22. Bertazzoni Minelli E, Della Bora T, Benini A. Different microbial biofilm formation on polymethylmethacrylate (PMMA) bone cement loaded with gentamicin and vancomycin. Anaerobe. 2011 Dec;17(6):380-3. PubMed PMID: 21515396.

23. Crick CR, Parkin IP. Preparation and characterisation of super-hydrophobic surfaces. Chemistry. 2010 Mar 22;16(12):3568-88. PubMed PMID: 20209527.

24. Knorr SD, Combe EC, Wolff LF, Hodges JS. The surface free energy of dental gold-based materials. Dental materials : official publication of the Academy of Dental Materials. 2005 Mar;21(3):272-7. PubMed PMID: 15705434.

25. Charman KM, Fernandez P, Loewy Z, Middleton AM. Attachment of Streptococcus oralis on acrylic substrates of varying roughness. Letters in applied microbiology. 2009 Apr;48(4):472-7. PubMed PMID: 19228292. 